\title{
Nanofibrous poly(3- hydroxybutyrate)/poly(3-hydroxyoctanoate) scaffolds provide a functional microenvironment for cartilage repair
}

Article

Accepted Version

Ching, K. Y., Andriotis, O. G., Li, S., Basnett, P., Su, B., Roy, I., Tare, R. S., Sengers, B. G. and Stolz, M. (2016) Nanofibrous poly(3-hydroxybutyrate)/poly(3-hydroxyoctanoate) scaffolds provide a functional microenvironment for cartilage repair. Journal of Biomaterials Applications, 31 (1). pp. 77-91. ISSN 1530-8022 doi:

https://doi.org/10.1177/0885328216639749 Available at https://centaur.reading.ac.uk/69775/

It is advisable to refer to the publisher's version if you intend to cite from the work. See Guidance on citing.

To link to this article DOI: http://dx.doi.org/10.1177/0885328216639749

Publisher: SAGE

All outputs in CentAUR are protected by Intellectual Property Rights law, including copyright law. Copyright and IPR is retained by the creators or other copyright holders. Terms and conditions for use of this material are defined in the End User Agreement. 


\section{www.reading.ac.uk/centaur}

\section{CentAUR}

Central Archive at the University of Reading

Reading's research outputs online 


\title{
Nanofibrous poly(3-hydroxybutyrate)/ poly(3-hydroxyoctanoate) scaffolds provide a functional microenvironment for cartilage repair
}

C) The Author(s) 2016

Reprints and permissions: sagepub.co.uk/journalsPermissions.nav DOI: $10.1177 / 0885328216639749$ jba.sagepub.com

(3)AGE

\author{
Kuan Y Ching', Orestis G Andriotiss,3, Siwei Li ${ }^{4}$, Pooja Basnett ${ }^{5}$, \\ Bo Su ${ }^{6}$, Ipsita Roy ${ }^{5}$, Rahul S Tare ${ }^{3,4}$, Bram G Sengers ${ }^{2}$ and \\ Martin Stolz'
}

\begin{abstract}
Articular cartilage defects, when repaired ineffectively, often lead to further deterioration of the tissue, secondary osteoarthritis and, ultimately, joint replacement. Unfortunately, current surgical procedures are unable to restore normal cartilage function. Tissue engineering of cartilage provides promising strategies for the regeneration of damaged articular cartilage. As yet, there are still significant challenges that need to be overcome to match the long-term mechanical stability and durability of native cartilage. Using electrospinning of different blends of biodegradable poly(3-hydroxybutyrate)/poly(3hydroxyoctanoate), we produced polymer scaffolds and optimised their structure, stiffness, degradation rates and biocompatibility. Scaffolds with a poly(3-hydroxybutyrate)/poly(3-hydroxyoctanoate) ratio of 1:0.25 exhibit randomly oriented fibres that closely mimic the collagen fibrillar meshwork of native cartilage and match the stiffness of native articular cartilage. Degradation of the scaffolds into products that could be easily removed from the body was indicated by changes in fibre structure, loss of molecular weight and a decrease in scaffold stiffness after one and four months. Histological and immunohistochemical analysis after three weeks of culture with human articular chondrocytes revealed a hyaline-like cartilage matrix. The ability to fine tune the ultrastructure and mechanical properties using different blends of poly(3hydroxybutyrate)/poly(3-hydroxyoctanoate) allows to produce a cartilage repair kit for clinical use to reduce the risk of developing secondary osteoarthritis. We further suggest the development of a toolbox with tailor-made scaffolds for the repair of other tissues that require a 'guiding' structure to support the body's self-healing process.
\end{abstract}

\section{Keywords}

Articular cartilage, tissue engineering, polyhydroxyalkanoates, electrospinning, atomic force microscopy, mechanical testing, osteoarthritis, biodegradable scaffolds

\section{Introduction}

Articular cartilage (AC) is a load-bearing tissue that acts as a shock absorber to protect the ends of the long bones in synovial joints and provides an almost frictionless gliding of the opposing bone surfaces, often over a lifetime. During the course of daily activities such as walking, stair climbing or squatting, the AC in the knee and hip joints is regularly loaded up to several times the body weight, which makes it susceptible to injuries by impact or torsional loadings. Due to the limited ability of AC to self-repair, AC is known as a tissue that 'once destroyed, is not repaired'. ${ }^{1}$ Hence, effective treatments are needed to prevent further degeneration of the lesion into secondary osteoarthritis.
'National Centre for Advanced Tribology at Southampton, Faculty of Engineering and the Environment, University of Southampton, UK

${ }^{2}$ Bioengineering Research Group, Faculty of Engineering and the Environment, University of Southampton, UK

${ }^{3}$ Institute of Lightweight Design and Structural Biomechanics, Vienna University of Technology, Austria

${ }^{4}$ Centre for Human Development, Stem Cells and Regeneration, Institute of Developmental Sciences, Faculty of Medicine, University of Southampton, UK

${ }^{5}$ Department of Life Sciences, Faculty of Science and Technology, University of Westminster, UK

${ }^{6}$ Biomaterials Engineering Group, School of Oral and Dental Sciences, University of Bristol, UK

\section{Corresponding author:}

Martin Stolz, National Centre for Advanced Tribology at Southampton, Faculty of Engineering and the Environment, University of Southampton, Highfield Campus, Southampton SOI7 IBJ, UK.

Email: m.stolz@soton.ac.uk 
Some first-line clinical treatments are based on marrow stimulation techniques, such as Pridie drilling, abrasion and microfracture. ${ }^{2-4}$ Unfortunately, marrow stimulation techniques produce predominantly fibrocartilage that largely consists of disorganised type I collagen fibrils, which are mechanically inferior and non-durable. ${ }^{3,5,6}$ Another widely used technique, the autologous chondrocyte transplantation (ACT), often leads to functionally weak fibrocartilage. ${ }^{7-10}$

Hydrogels such as collagen, ${ }^{11,12}$ hyaluronan, ${ }^{13}$ chit$\mathrm{osan}^{14}$ and poly(ethylene glycol) $(\mathrm{PEG})^{6,15}$ have been tested in clinical studies. A few products have obtained regulatory status. ${ }^{11,13-15}$ In addition, the liquid precursors of chitosan ${ }^{14}$ and $\mathrm{PEG}^{6,15}$ were combined with the microfracture technique to provide a three-dimensional (3D) environment for the differentiation of bone marrow stem cells into chondrocytes. However, hydrogels cannot withstand the joint loading forces and deteriorate easily. The mismatch of mechanical properties between the hydrogel and the surrounding host tissue induces shear stresses on the interfaces, which prevents the ingrowth of new cartilage. When increasing the polymer concentration to match the stiffness of native cartilage, the result is a reduction of cell viability. ${ }^{16}$ This unsatisfactory behaviour of hydrogels for cartilage repair may be explained by comparing hydrogels with cartilage. AC exhibits two principle matrix components, the proteoglycans and the collagen fibril meshwork, which are acting in concert and are responsible for the tissue's functional properties, whereas a hydrogel is only a structural simple amorphous material that cannot mimic the tissue complexity. When cells anchor to the surrounding matrix, the differences in cell-matrix interactions and the altered stimuli of the cell surface receptors lead to changes in the cell signalling pathways, protein synthesis and altered tissue formation. The lack of integration of the engineered cartilage, as well as the differences in the structural and mechanical properties between scaffolds and the surrounding native cartilage may be the main reasons for the development of fibrous cartilage.

Another popular class of structural supports is $\operatorname{poly}(\alpha$-hydroxy acids) polymers such as poly(glycolic acid) and poly(lactic acid). ${ }^{17-19}$ Their copolymers, poly(lactic-co-glycolic acid) (PLGA), are Food and Drug Administration approved biomaterials that have been employed as resorbable suture materials for several decades. More recently, PLGA has also been employed for repairing chondral and osteochondral defects. ${ }^{20,21}$ To mimic the collagen fibril meshwork of $\mathrm{AC}$, the polymers have been fabricated into meshworks of electrospun fibres. ${ }^{19,22}$ It was reported that the rapid degradation of these co-polymers increased the acidity in the microenvironment, which reduced cell viability

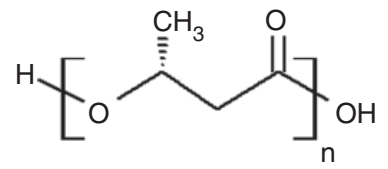

Figure I. General structure of PHAs; R indicating the alkyl side group.

and cell migration into the scaffolds. ${ }^{23}$ The release of acidic by-products leads to inflammations in the host body, particularly in orthopaedic applications where larger-sized implants are often required. ${ }^{24-26}$

A major hurdle in the engineering of cartilage is the de-differentiation of chondrocytes when exposed to a synthetic microenvironment, ${ }^{27}$ which often results in the development of calcified or fibrous cartilage. The dependence of cell fate on the microenvironment is well-known in stem cell research. Stem cells differentiate into the specific mature tissue cells when being exposed to the microenvironment of their extracellular matrix. ${ }^{28}$ The dominating role of the microenvironment in directing tissue development has been most impressively demonstrated in cancer research, where in a series of experiments normal cells were turned into cancer cells, and reversed back into normal cells by changing the (micro-) environment. ${ }^{29-31}$ Inspired by those findings, we aim to develop a cartilage-specific extracellular matrix to provide a microenvironment that mimics native cartilage and that favours neo-cartilage growth. Once new functional cartilage grows into the defect site, the polymer fibrils degrade into biocompatible smallsized molecules and are transported as waste material out of the body. To achieve these key requirements, biodegradable polyhydroxyalkanoates (PHAs), which exhibit a wide range of structural, physicochemical and thermal properties, are employed in this research. PHAs are a family of biopolyesters synthesised by a wide variety of bacteria under the conditions of limiting nutrients but excess carbon source. Figure 1 shows the general structure of PHAs. Depending on the length of the alkyl side group, $\mathrm{R}$, poly(3-hydroxybutyrate) is a short-chain-length PHA with $\mathrm{R}$ represented by a methyl group $\left(\mathrm{CH}_{3}\right)$, while $\mathrm{P}(3 \mathrm{HO})$ is a mediumchain-length PHA with $\mathrm{R}$ represented by a pentyl group $\left(\mathrm{C}_{5} \mathrm{H}_{11}\right)$. By blending PHAs of different chain lengths, their properties can be optimised for biomedical application and in particular for cartilage repair, where mechanical and biodegradation properties are important. $\mathrm{P}(3 \mathrm{HB})$ has been investigated for tissue engineering applications that require longer retention times or high mechanical stability within the surrounding environment ${ }^{32}$ and can be modified with human procollagen to improve cell adhesion and proliferation. ${ }^{33}$ 
We produced fibrous poly(3-hydroxybutyrate)/ poly(3-hydroxyoctanoate) $\mathrm{P}(3 \mathrm{HB}) / \mathrm{P}(3 \mathrm{HO})$ scaffolds that: (i) exhibit an ultrastructure similar to the collagen fibrillar meshwork in native cartilage, (ii) provide a temporary mechanical support for the chondrocytes with a similar microenvironment compared to the collagen meshwork in native $\mathrm{AC}$ until functional neo-cartilage is formed and (iii) are biodegradable and resorbable to avoid the accumulation of foreign material in the body. It is important that the ultrastructure and the mechanical properties are the keys for a microenvironment that favours neo-cartilage growth and without any one of these features, a scaffold will not support cartilage repair. In addition, we demonstrated that varying the composition of the $\mathrm{P}(3 \mathrm{HB}) / \mathrm{P}(3 \mathrm{HO})$ blends allows to optimise the degradation rates. This is important as the optimum scaffold degradation kinetics are obtained when the scaffold continues to degrade and lose its mechanical integrity, while the newly formed neo-cartilage becomes the predominant mechanical supporting structure to enable successful tissue regeneration. ${ }^{34,35}$

\section{Materials and methods}

\section{Fabrication of $\mathrm{P}(3 \mathrm{HB}) / \mathrm{P}(3 \mathrm{HO})$ scaffolds}

$\mathrm{P}(3 \mathrm{HB})$ was isolated from the Gram-positive bacterium Bacillus cereus SPV and $\mathrm{P}(3 \mathrm{HO})$ from the Gram-negative bacterium Pseudomonas mendocina as previously described by Rai and co-workers. ${ }^{36,37}$ The molecular weight, $M_{w}$, of $\mathrm{P}(3 \mathrm{HB})$ was $181,343 \mathrm{~g} / \mathrm{mol}$ with a polydispersity index of 3.57 , whereas the $M_{w}$ of $\mathrm{P}(3 \mathrm{HO})$ was $222,270 \mathrm{~g} / \mathrm{mol}$ with a polydispersity index of 3.73 . Solid $\mathrm{P}(3 \mathrm{HB})$ and $\mathrm{P}(3 \mathrm{HO})$ in $\mathrm{P}(3 \mathrm{HB}) / \mathrm{P}(3 \mathrm{HO})$ ratios of $1: 0.25$, 1:0.43, 1:0.67, 1:1 were dissolved in chloroform (288306; Sigma-Aldrich, Gillingham, UK) separately at $30 \mathrm{wt} . \%$. The dissolved $\mathrm{P}(3 \mathrm{HB}) / \mathrm{P}(3 \mathrm{HO})$ in chloroform were then mixed together for electrospinning. Electrospinning was employed using a solution flow rate of $5 \mu \mathrm{l} / \mathrm{min}$, a high voltage supply of $\sim 12 \mathrm{kV}$ and a distance between the spinneret and collector of $\sim 20 \mathrm{~cm}$.

\section{Preparation of human AC}

Human AC was obtained from the femoral head of patients undergone total hip replacement surgery at the Southampton General Hospital, with the approval of the Southampton General Hospital and South West Hants Local research Ethnics Committee (LREC 194/ 99/1 and 210/01). Cartilage samples were taken from areas with no apparent signs of damage or disease and stored in minimum essential medium alpha medium (MEM $\alpha, 11900$; Life Technologies, Paisley, UK) on ice or at $4{ }^{\circ} \mathrm{C}$ until use.

\section{Scanning electron microscopy}

Scanning electron microscopy (SEM) was employed following enzymatic digestion of proteoglycans and cells of AC samples in phosphate-buffered solutions (PBS, H15-002; PAA Laboratories, Pasching, Austria) containing $1 \mathrm{mg} / \mathrm{ml}$ bovine hyaluronidase (type I, H3506; Sigma-Aldrich) and $1 \mathrm{mg} / \mathrm{ml}$ trypsin (Trypsin-EDTA, T4174; Sigma-Aldrich) at $37^{\circ} \mathrm{C}$ for three days. ${ }^{38}$ Specimens were then fixed with $4 \%$ paraformaldehyde $(\mathrm{P} / 0840 / 53$; Fisher Scientific, Loughborough, UK) in PBS for $4 \mathrm{~h}$ at room temperature, rinsed with water and dehydrated in graded ethanol series. Prior to SEM imaging, all samples were gold coated with a Hummer 6.2 Sputter System (Anatech, Union City, CA). SEM (JSM-6500 F; JEOL, Tokyo, Japan) imaging at an accelerating voltage of $10 \mathrm{kV}$ revealed the meshwork structure and the fibril width to a depth of $\sim 0.25$.

\section{Fourier transform infrared spectroscopy}

Fourier transform infrared spectroscopy (FTIR) was employed to identify the presence of chemical functional groups in polymers. A FTIR spectrometer (Thermo Nicolet 380; Thermo Electron Scientific Instrument, Madison, WI) equipped with a Smart Orbit detector and the OMNIC 32 software was employed to record FTIR spectra in the range of $4000-400 \mathrm{~cm}^{-1}$ at a resolution of $8 \mathrm{~cm}^{-1}$. A total of 32 scans were used for signal averaging. The analysis was repeated three times for each sample.

\section{Indentation-type atomic force microscopy}

Stiffness was measured by indentation-type atomic force microscopy (IT-AFM; MFP-3D; Asylum Research, Santa Barbara, CA) in PBS solution following protocols developed by our group. ${ }^{38-40}$ Spherical probes were prepared by gluing hard borosilicate glass spheres (radius, $r=5 \mu \mathrm{m}, 02715-\mathrm{AB}$; SPI Supplies, West Chester, PA) onto tipless rectangular cantilever (spring constant, $k_{c} \sim 6 \mathrm{~N} / \mathrm{m}$, type All In One-TL; BudgetSensors, Sofia, Bulgaria). A maximum deflection of $100 \mathrm{~nm}$ was employed, corresponding to a load of $\sim 600 \mathrm{nN}$. Cyclic load-displacement curves were recorded at $0.5 \mathrm{~Hz}$. Each individual data set consisted of 1024 load-displacement curves in a $32 \times 32$ curve grid, covering a sample area of $30 \times 30 \mu \mathrm{m}$, at three different locations. The indentation depths were less than $10 \%$ of the overall sample thickness. ${ }^{41}$ The stiffness of sample, $E$, was calculated from equation (1). ${ }^{42}$

$$
E=\frac{\sqrt{\pi}}{2}\left(1-v^{2}\right) \frac{S}{\sqrt{A}}
$$


where $v$ is the Poisson's ratio of the sample, $S$ is the contact stiffness with the dimension of force per unit depth, $A$ is the projected contact area.

\section{Degradation of scaffolds}

The degradation of unseeded scaffolds was tested in MEM $\alpha$ medium at $37^{\circ} \mathrm{C}$. The medium was changed every two days. After one and four months, the degraded scaffolds were examined by SEM and IT-AFM. In addition, the molecular weight of the scaffolds was analysed by gel permeation chromatography (1090 HPLC; Hewlett-Packard, Burlington, MA) equipped with UV-Visible and differential refractive index detectors. Dried samples were dissolved in chloroform at a concentration of $0.10 \mathrm{mg} / \mathrm{ml}$ and eluted through PLgel $5 \mu \mathrm{m}$ Mixed C column (Polymer Laboratories, Church Stretton, UK) at a flow rate of $1 \mathrm{ml} / \mathrm{min}$. A polystyrene standard was used to calibrate the instrument prior to measurements. The Cirrus GPC software was employed for analysing data.

\section{In vitro biocompatibility of scaffolds}

The focus of this work was to investigate if we can produce $\mathrm{P}(3 \mathrm{HB}) / \mathrm{P}(3 \mathrm{HO})$ scaffolds with stiffness comparable to those of native cartilage to support chondrogenesis. Human articular chondrocytes (HACs) were isolated from the cartilage specimens following digestion in $1 \times$ trypsin-EDTA for $30 \mathrm{~min}, 1 \mathrm{mg} / \mathrm{ml}$ hyaluronidase for $15 \mathrm{~min}$ and $10 \mathrm{mg} / \mathrm{ml}$ collagenase B (11088831001; Roche Diagnostics, West Sussex, UK) for $15 \mathrm{~h} .{ }^{43}$ The isolated HACs were then expanded in MEM $\alpha$ supplemented with $10 \%$ foetal bovine serum (FBS, 10270-106; Life Technologies), 100 unit/ml penicillin, $100 \mu \mathrm{g} / \mathrm{ml}$ streptomycin (Penicillin-Streptomycin, P4333; Sigma-Aldrich) and $100 \mu \mathrm{M}$ L-ascorbic acid 2-phosphate sequimagnesium salt hydrate (A8960; Sigma-Aldrich). The HACs were harvested at confluence by trypsinization $(1 \times$ trypsin-EDTA $)$ after one passage. Scaffolds were sterilised with absolute ethanol, rinsed with PBS, and seeded with HACs at a density of $\sim 7 \times 10^{5}$ cells $/ \mathrm{cm}^{2}$. The HACs-seeded scaffolds were cultured in chondrogenic induction medium made up of MEM $\alpha$ supplemented with $10 \mathrm{ng} / \mathrm{ml}$ recombinant human transforming growth factor- $\beta 3$ (TGF- $\beta 3,100-$ $36 \mathrm{E}$; Peprotech, London, UK), $100 \mu \mathrm{M}$ L-ascorbic acid 2-phosphate sequimagnesium salt hydrate, $10 \mathrm{nM}$ dexamethasone (D4902; Sigma-Aldrich), and $1 \times$ Insulin-Transferrin-Selenium-G (ITS-G, 41400; Life Technologies). ${ }^{44}$ All tissue cultures were incubated at $37^{\circ} \mathrm{C}$ in humidified atmosphere with $5 \% \quad \mathrm{CO}_{2}$. Media were exchanged every two days. The constructs were harvested for live/dead cell staining, histological and immunohistochemical analysis, and stiffness measurement after three weeks. At least three samples were tested in each experiment.

Live/dead cell staining. Metabolically active cells were labelled with $10 \mu \mathrm{g} / \mathrm{ml}$ Cell Tracker Green CMFDA (5-chloromethylfluorescein diacetate, C7025; Life Technologies), while necrotic cells were labelled with $5 \mu \mathrm{g} / \mathrm{ml}$ Ethidium Homodimer-1 (E1169; Life Technologies) for an hour. After incubation in tissue culture medium for $45 \mathrm{~min}$, the constructs were fixed with $4 \%$ paraformaldehyde in PBS. The specimens were embedded in paraffin wax and sequential sections were cut in sections of $7 \mu \mathrm{m}$. After de-waxing with Histoclear (HS200; National Diagnostics, Leicestershire, UK) and re-hydration through graded ethanol, cell nuclei were stained with DAPI $\left(4^{\prime}, 6-\right.$ diamidino-2-phenylindole, dilactate, D3571; Life Technologies). Fluorescent images were acquired with Axiovert 200 microscope (Carl Zeiss Microscopy, Jena, Germany) equipped with Zeiss AxioCam HR colour camera, AxioCam MR3 monochrome camera and the Zeiss AxioVision 4.6 software.

Histology and immunohistochemistry. After de-waxing with Histoclear and re-hydrating through graded ethanol, cell nuclei were counter-stained with haematoxylin $(\mathrm{H} / 0010 / 46$; Fisher Scientific). The proteoglycan content was stained with $5 \mathrm{mg} / \mathrm{ml}$ Alcian blue $8 \mathrm{GX}$ (40046-0100; Acros Organics, Geel, Belgium), while total collagen content was stained with $10 \mathrm{mg} / \mathrm{ml}$ Direct Red 80 (365548; Sigma-Aldrich).

The expression of SOX-9, aggrecan, collagen I, II and $\mathrm{X}$ in the neo-cartilage was detected by immunohistochemistry. For anti-SOX-9 and anti-aggrecan antibodies, sections were treated with heat-induced antigen retrieval in $0.01 \mathrm{M}$ citrate buffer at $60^{\circ} \mathrm{C}$ for $25 \mathrm{~min}$, followed by quenching endogeneous peroxidase with $3 \%$ hydrogen peroxide $\left(\mathrm{H}_{2} \mathrm{O}_{2}\right)$ and blocking with $1 \%$ bovine serum albumin (A3294, Sigma-Aldrich) in PBS. For anti-collagen I, II and $\mathrm{X}$ antibodies, sections were quenched with $3 \% \mathrm{H}_{2} \mathrm{O}_{2}$, incubated with $520 \mu \mathrm{g} / \mathrm{ml}$ bovine hyaluronidase at $37^{\circ} \mathrm{C}$ for $20 \mathrm{~min}$ and then blocked with $1 \%$ bovine serum albumin. Next, sections were incubated with the relevant primary antibody at $4^{\circ} \mathrm{C}$ for $18 \mathrm{~h}$. The anti-SOX-9 (AB5535; Millipore, Billerica, MA) and anti-aggrecan (ab36861; Abcam, Cambridge, UK) antibodies were used at dilution of 1:150, anti-collagen I antibody (gift from Larry W. Fisher, National Institutes of Health, Maryland) at 1:1000, anti-collagen II (ab34712; Abcam) and anti-collagen X (234196; Millipore) antibodies at 1:100. This was followed by incubation with biotinylated secondary antibody (B7389; Sigma Aldrich) at a dilution of 1:100 for an hour. Visualisation of the immune complex involved the avidin-biotin method linked to peroxidase 

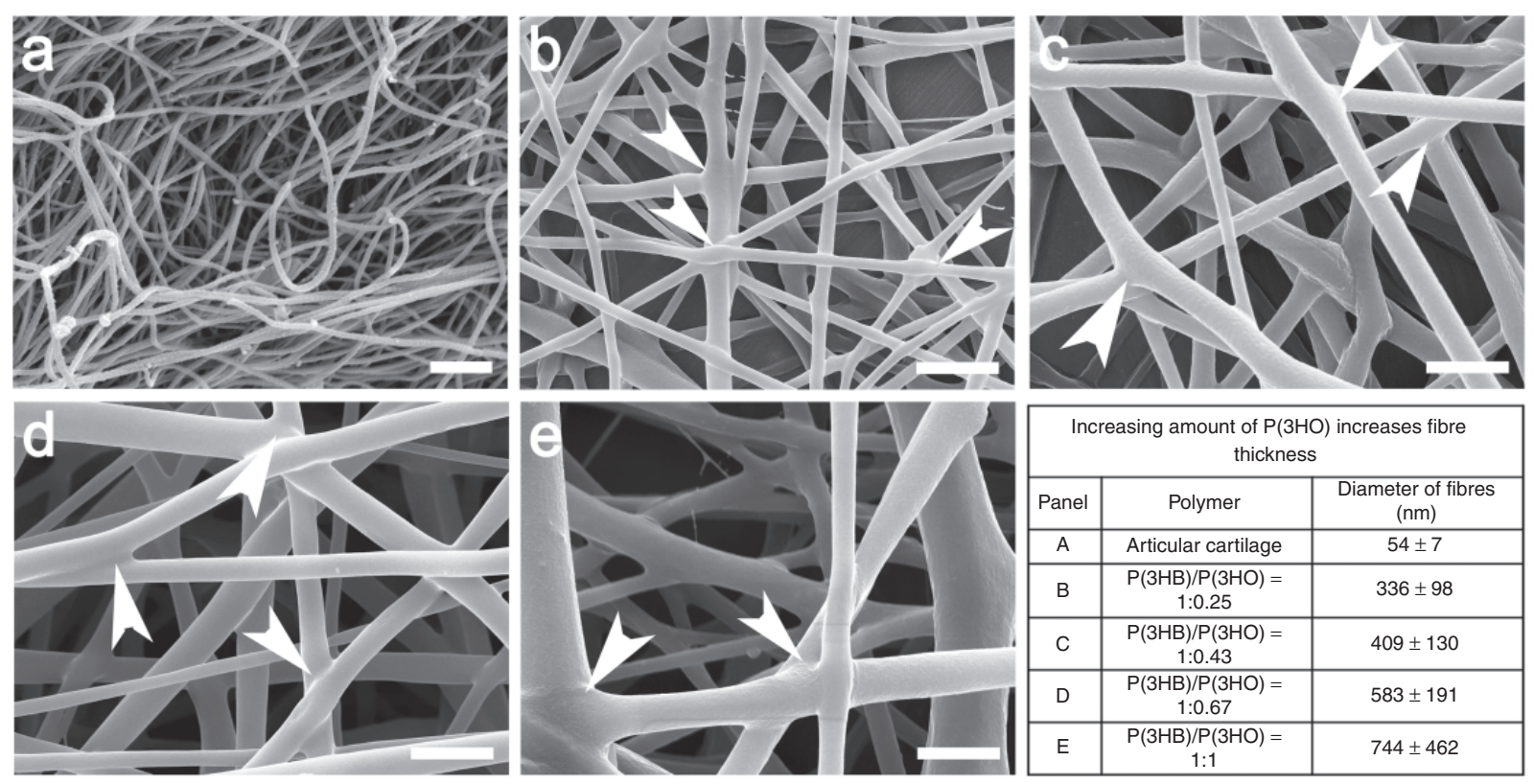

\begin{tabular}{|c|c|c|}
\hline \multicolumn{3}{|c|}{$\begin{array}{c}\text { Increasing amount of } \mathrm{P}(3 \mathrm{HO}) \text { increases fibre } \\
\text { thickness }\end{array}$} \\
\hline Panel & Polymer & $\begin{array}{c}\text { Diameter of fibres } \\
(\mathrm{nm})\end{array}$ \\
\hline$A$ & Articular cartilage & $54 \pm 7$ \\
\hline$B$ & $\begin{array}{c}\mathrm{P}(3 \mathrm{HB}) / \mathrm{P}(3 \mathrm{HO})= \\
1: 0.25\end{array}$ & $336 \pm 98$ \\
\hline C & $\begin{array}{c}\mathrm{P}(3 \mathrm{HB}) / \mathrm{P}(3 \mathrm{HO})= \\
1: 0.43\end{array}$ & $409 \pm 130$ \\
\hline$D$ & $\begin{array}{c}\mathrm{P}(3 \mathrm{HB}) / \mathrm{P}(3 \mathrm{HO})= \\
1: 0.67\end{array}$ & $583 \pm 191$ \\
\hline$E$ & $\begin{array}{c}\mathrm{P}(3 \mathrm{HB}) / \mathrm{P}(3 \mathrm{HO})= \\
1: 1\end{array}$ & $744 \pm 462$ \\
\hline
\end{tabular}

Figure 2. Comparison of SEM micrographs of the $A C$ collagen meshwork with electrospun $P(3 H B) / P(3 H O)$ fibres. (a) The collagen fibril meshwork of human $A C$ after proteoglycan extraction exhibits a pseudo-random meshwork of smooth collagen fibrils with diameters of $54 \pm 7 \mathrm{~nm}$. (b-e) Electrospun fibres with different diameters were fabricated from different ratios of $\mathrm{P}(3 \mathrm{HB}) / \mathrm{P}(3 \mathrm{HO})$. All $\mathrm{P}(3 \mathrm{HB}) / \mathrm{P}(3 \mathrm{HO})$ fibres exhibit smooth surfaces, random orientations of fibres and increasing diameters with an increasing amount of $\mathrm{P}(3 \mathrm{HO})$ as shown in the Table. Crosslinkages between some fibres can be observed as indicated by the white arrow heads. Scale bars: $500 \mathrm{~nm}(\mathrm{a}), 2 \mu \mathrm{m}(\mathrm{b}-\mathrm{e})$.

(ExtrAvidin Peroxidase, E2886; Sigma-Aldrich) at a dilution of 1:50 and 3-amino-9-ethylcarbazole (AEC, 132-32-1; Acros Organics, New Jersey). The reaction products were reddish brown in colour. Negative controls (omission of the primary antibody) were included in the control sections. Images were captured using an inverted light microscope (type BX51, Olympus Corporation, Tokyo, Japan) equipped with a dotSlide virtual slide system.

\section{Results}

\section{Electrospun $\mathrm{P}(3 \mathrm{HB}) / \mathrm{P}(3 \mathrm{HO})$ fibres}

Electrospinning of polymer blends with different ratios of $\mathrm{P}(3 \mathrm{HB}) / \mathrm{P}(3 \mathrm{HO})$ produced solid fibres with random orientation. Values for fibre diameters represent averages over approximately 50 fibres. As shown in Figure 2(b) to (e), the electrospun fibres exhibit larger fibre sizes compared to the collagen fibrils in human AC (Figure 2(a)). The scaffold with $\mathrm{P}(3 \mathrm{HB}) / \mathrm{P}(3 \mathrm{HO})$ ratio of 1:0.25 exhibited the smallest fibre diameter of $336 \pm 98 \mathrm{~nm}$, which is approximately sixfold larger compared to the diameter of the collagen fibrils. The scaffolds remained stable after immersing in the PBS solution for up to seven days (results not shown).

FTIR was employed to obtain structural information of the individual $\mathrm{P}(3 \mathrm{HB})$ and $\mathrm{P}(3 \mathrm{HO})$ polymers and of the blends. As shown in Figure 3, the most prominent absorption band in all the FTIR spectra is visible at $\sim 1720 \mathrm{~cm}^{-1}$, corresponding to the absorption band of the ester carbonyl group $(\mathrm{C}=\mathrm{O})$, which is the main functional group of PHAs. The highly crystalline $\mathrm{P}(3 \mathrm{HB})$ shows a lower $\mathrm{C}=\mathrm{O}$ absorption band, at $1720 \mathrm{~cm}^{-1}$. The blends of $\mathrm{P}(3 \mathrm{HB}) / \mathrm{P}(3 \mathrm{HO})$ also exhibited $\mathrm{C}=\mathrm{O}$ absorption bands at similar wavenumbers, $\sim 1721-1722 \mathrm{~cm}^{-1}$. The $\mathrm{C}=\mathrm{O}$ absorption band was at $1729 \mathrm{~cm}^{-1}$ for $\mathrm{P}(3 \mathrm{HO})$, reflecting the more amorphous nature of $\mathrm{P}(3 \mathrm{HO}){ }^{45}$

\section{Stiffness of scaffolds}

Using spherical indenters with $r=5 \mu \mathrm{m}$, the overall stiffness properties of the various structural elements composing $\mathrm{AC}$ and the stiffness properties of electrospun fibrous meshworks were measured. Figure 4 documents the stiffness of scaffolds with four different blend compositions of $\mathrm{P}(3 \mathrm{HB}) / \mathrm{P}(3 \mathrm{HO})$, which are compared to the stiffness of the superficial zone and deep zone of native AC.

Superficial AC cartilage stiffness was measured on the original cartilage surface, whereas deep zone cartilage was measured after removal of the superficial and middle zones $(\sim 2 \mathrm{~mm})$. The stiffness was higher for lower content of the soft and elastomeric $\mathrm{P}(3 \mathrm{HO})$, with a stiffness of $868 \pm 540 \mathrm{kPa}$ for the 


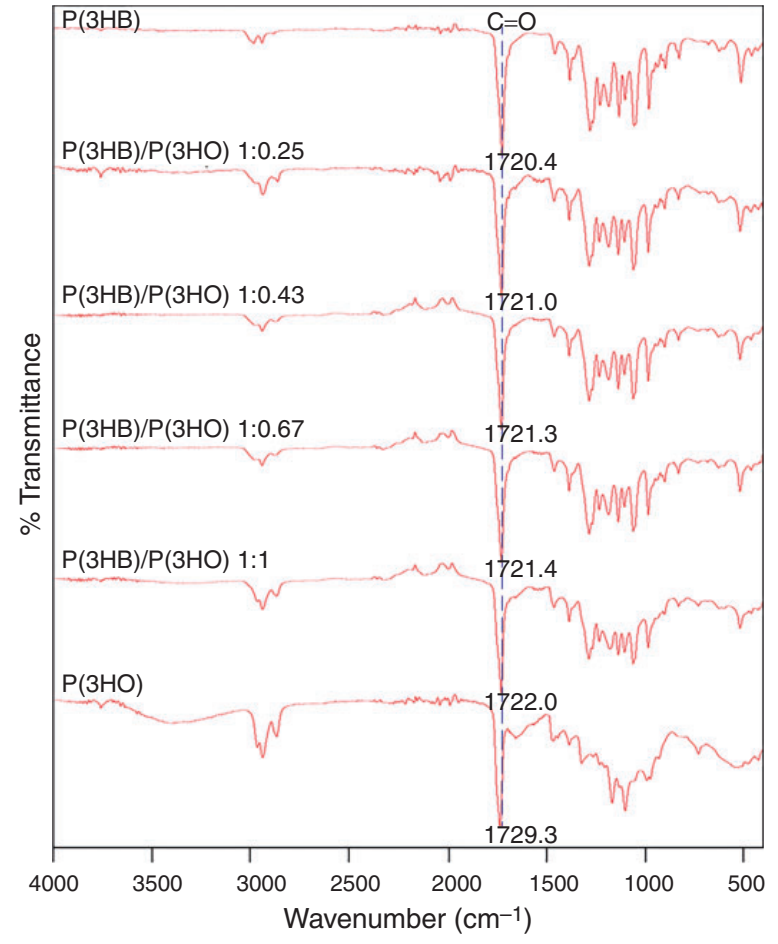

Figure 3. The shift in the infrared absorption band of $\mathrm{C}=\mathrm{O}$ indicates the effect of hydrogen bond. FTIR spectra comparing neat $\mathrm{P}(3 \mathrm{HB})$, neat $\mathrm{P}(3 \mathrm{HO})$ and the four different blends of $\mathrm{P}(3 \mathrm{HB}) / \mathrm{P}(3 \mathrm{HO})$. The $\mathrm{C}=\mathrm{O}$ absorption band at $\sim 1720 \mathrm{~cm}^{-1}$ slightly shifted to higher wavenumbers with increasing amount of $\mathrm{P}(3 \mathrm{HO})$.
$\mathrm{P}(3 \mathrm{HB}) / \mathrm{P}(3 \mathrm{HO}) \quad 1: 0.25$ scaffold, corresponding to $\sim 53 \%$ of the stiffness of AC measured in the deep zone $(1854 \pm 483 \mathrm{kPa})$ and is $\sim 45 \%$ higher than the stiffness of AC measured at the superficial zone $(600 \pm 150 \mathrm{kPa})$. The stiffness of $\mathrm{P}(3 \mathrm{HB}) / \mathrm{P}(3 \mathrm{HO})$ 1:0.43 scaffold was $654 \pm 505 \mathrm{kPa}$, which is similar to the stiffness of superficial zone AC. Both the stiffness of scaffolds with $\mathrm{P}(3 \mathrm{HB}) / \mathrm{P}(3 \mathrm{HO})$ ratios of $1: 0.67$ and $1: 1$ were measured as $274 \pm 222 \mathrm{kPa}$ and $346 \pm 205 \mathrm{kPa}$, respectively.

\section{Degradation of scaffolds}

As documented in Figure 5 (a) to (d), changes of fibre size and morphology were observed after one and four months (Figure 5 (e) to (h)). During initial degradation $(t=1$ month), fibres of all samples appeared swollen. The average fibre diameter increased by $67 \%$ compared to $t=0$ for $\mathrm{P}(3 \mathrm{HB}) / \mathrm{P}(3 \mathrm{HO})$ ratio of $1: 0.25,40 \%$ for $1: 0.43,59 \%$ for $1: 0.67$ and $22 \%$ for $1: 1$. After four months, some of the fibres had been degraded into smaller sized fibres and the individual fibre boundaries were indistinguishable. Most of the fibre sizes were reduced by approximately $13-24 \%$ compared to their size at $t=1$ month (Figure 5(i)). Despite the progressive degradation at four months, the overall fibre structure as well as the structure of the scaffold remained morphologically intact.

As shown in Figure 6, the stiffness of scaffolds decreased gradually with increasing degradation. At one month, the stiffness of $\mathrm{P}(3 \mathrm{HB}) / \mathrm{P}(3 \mathrm{HO}) 1: 0.25$

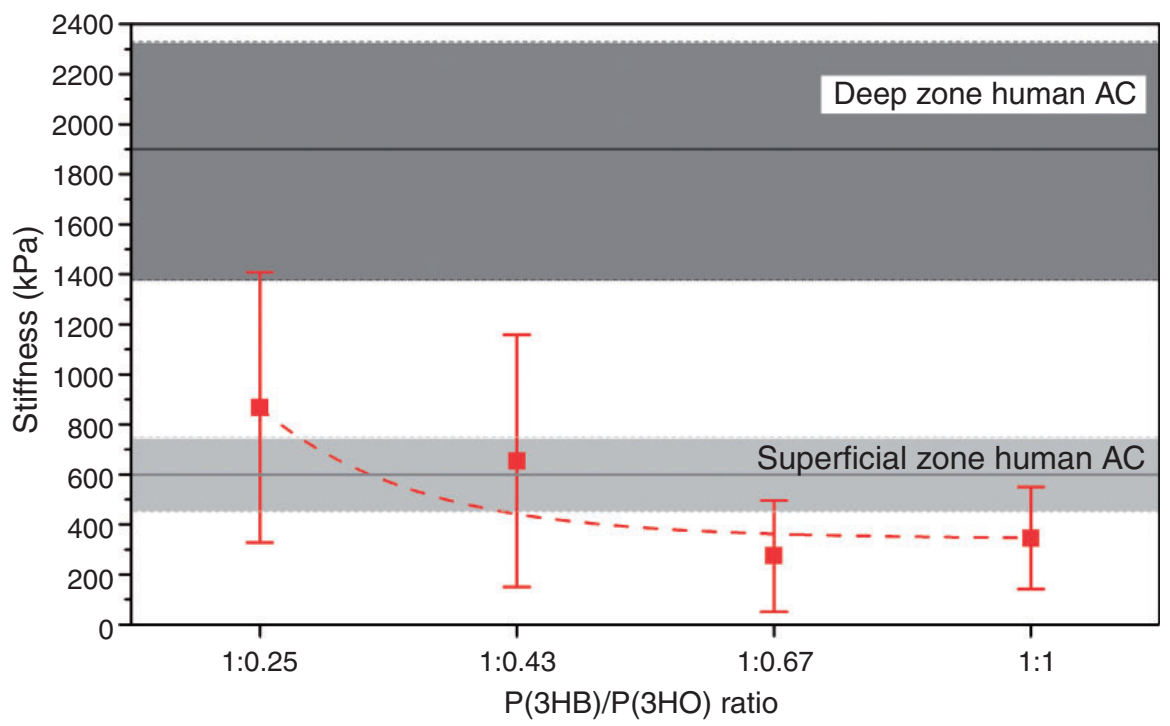

Figure 4. Stiffness measurements of the $\mathrm{P}(3 \mathrm{HB}) / \mathrm{P}(3 \mathrm{HO})$ scaffolds in comparison to human $\mathrm{AC}$. As indicated by the dashed curve, the stiffness of scaffolds decreases with the increasing amount of $\mathrm{P}(3 \mathrm{HO})$. The area in light grey shows the range of stiffness measured on the superficial zone of human AC, whereas the area in dark grey shows the range of stiffness measured on the deep zone human AC. 


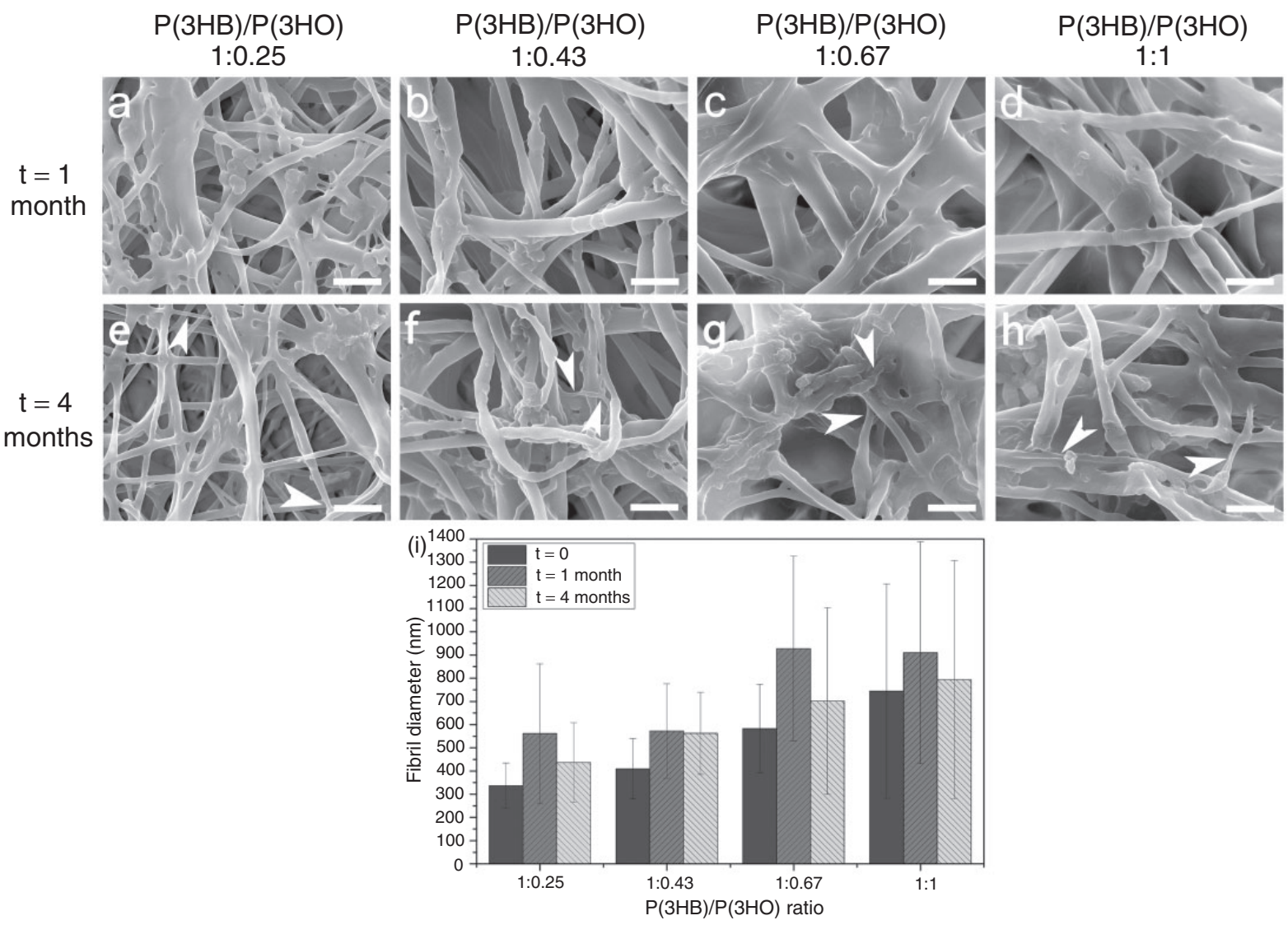

Figure 5. Comparison of SEM micrographs of the scaffolds after hydrolytic degradation. (a-d) After I month of hydrolytic degradation the fibres show larger variations in thickness compared to the original fibres shown in Figure I. A few fibres became thinner, whereas the majority of fibres look thicker and some of the fibres were fused together. (e-h) After 4 months of degradation some of the fibres show a reduced thickness (white arrow heads). The mesh size of the scaffold was reduced because some of the fibres were fused together. (i) The average diameters of fibres increased after I month degradation and decreased after 4 months. Scale bars: $2 \mu \mathrm{m}$.

scaffold reduced by $34 \%$ to $577 \pm 475 \mathrm{kPa}$, which was still similar to the stiffness of superficial zone human AC. At four months, the stiffness further reduced by a total of $76 \%$, to $206 \pm 173 \mathrm{kPa}$. In comparison, the stiffness of $\mathrm{P}(3 \mathrm{HB}) / \mathrm{P}(3 \mathrm{HO}) 1: 0.43$ scaffold reduced by $65 \%$ to $230 \pm 178 \mathrm{kPa}$ after one month, and further reduced by a total of $82 \%$, to $119 \pm 53 \mathrm{kPa}$ after four months. Similarly, the stiffness of scaffolds with $\mathrm{P}(3 \mathrm{HB}) / \mathrm{P}(3 \mathrm{HO})$ ratios of 1:0.67 and 1:1 after four months of degradation reduced to $186 \pm 120 \mathrm{kPa}$ and $108 \pm 44 \mathrm{kPa}$, respectively.

To further evaluate the scaffold degradation, we measured the molecular weight loss, $M_{w}$, of scaffolds with the $\mathrm{P}(3 \mathrm{HB}) / \mathrm{P}(3 \mathrm{HO})$ ratios of $1: 0.25$ and $1: 0.43$. The $\mathrm{P}(3 \mathrm{HB}) / \mathrm{P}(3 \mathrm{HO}) 1: 0.25$ scaffold exhibited a $M_{w}$ loss of $19 \%$ and $27 \%$ after one and four months, respectively. The $M_{w}$ loss on $\mathrm{P}(3 \mathrm{HB}) / \mathrm{P}(3 \mathrm{HO}) 1: 0.43$ scaffold was slightly lower, with $9 \%$ and $12 \%$ of $M_{w}$ loss after one and four months, respectively. Both the scaffolds showed a higher rate of $M_{w}$ loss at one month in comparison to four months.

\section{In vitro biocompatibility of scaffolds}

HACs were seeded into the two scaffolds with the highest stiffness, i.e. $\mathrm{P}(3 \mathrm{HB}) / \mathrm{P}(3 \mathrm{HO})$ ratios of $1: 0.25$ and 1:0.43. After three weeks of static culturing, the constructs transitioned from a loose fibrous meshwork into a tissue-like material, with a smooth and shiny appearance. To examine the presence of live and dead cells in the scaffolds, a fluorescent double staining protocol using Cell Tracker Green and Ethidium Homodimer1 was employed. Figure 7 shows the representative fluorescence images of the HACs-seeded scaffolds. The HACs had migrated into the voids and spaces between fibrils. By counting the amount of live and dead cells, the cell viability on the scaffolds was over $98 \%$, with negligible number of necrotic cells (red fluorochromes $)$. All $\mathrm{P}(3 \mathrm{HB}) / \mathrm{P}(3 \mathrm{HO})$ scaffolds demonstrated a similar high degree of cell viability, regardless of the blend compositions (results not shown).

Figure 8(a) and $\left(a^{\prime}\right)$, reveals the composition of extracellular matrix by histological staining. 


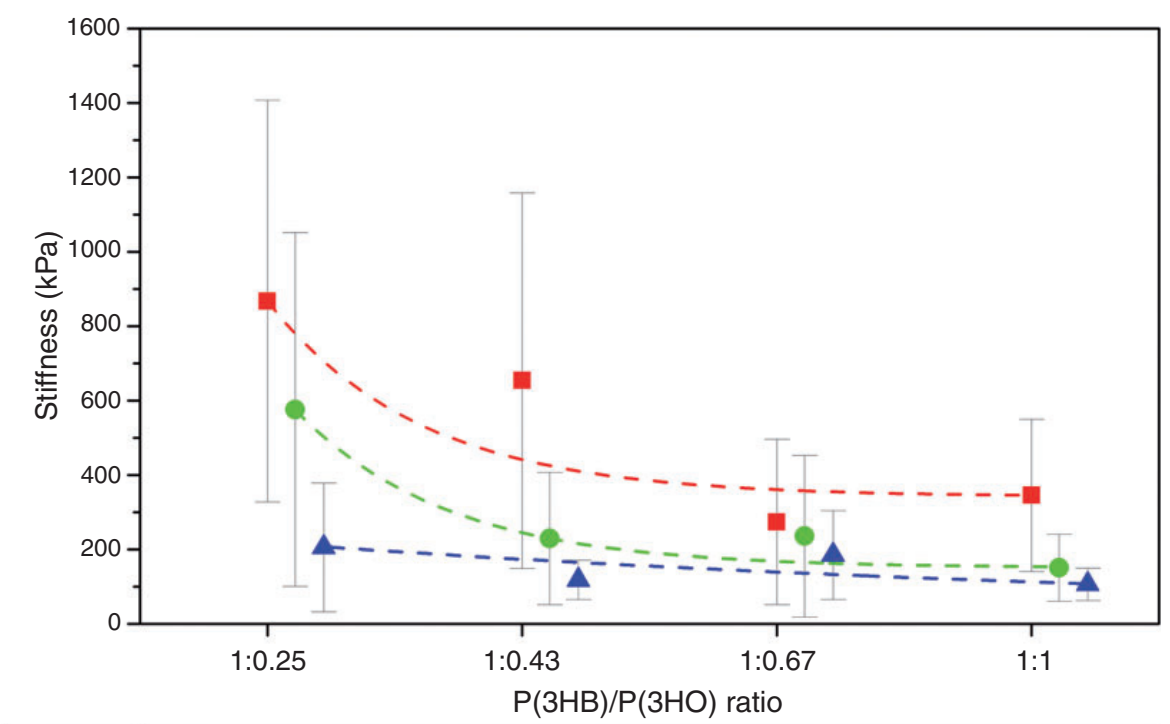

\begin{tabular}{|c|c|c|c|c|}
\hline \multirow{2}{*}{ Time } & \multicolumn{4}{|c|}{ Stiffness $(\mathrm{kPA})$} \\
\cline { 2 - 5 } (month) & $\mathrm{P}(3 \mathrm{HB}) / \mathrm{P}(3 \mathrm{HO})=$ & $\mathrm{P}(3 \mathrm{HB}) / \mathrm{P}(3 \mathrm{HO})=$ & $\mathrm{P}(3 \mathrm{HB}) / \mathrm{P}(3 \mathrm{HO})=$ & $\mathrm{P}(3 \mathrm{HB}) / \mathrm{P}(3 \mathrm{HO})=$ \\
& $1: 0.25$ & $1: 0.43$ & $1: 0.67$ & $1: 1$ \\
\hline 0 & $868 \pm 540$ & $654 \pm 505$ & $274 \pm 222$ & $346 \pm 205$ \\
\hline 1 & $577 \pm 475$ & $230 \pm 178$ & $236 \pm 217$ & $151 \pm 90$ \\
\hline 4 & $206 \pm 173$ & $119 \pm 53$ & $186 \pm 120$ & $107 \pm 44$ \\
\hline
\end{tabular}

Figure 6. Decrease in the stiffness of scaffolds after hydrolytic degradation. The red curve shows the original stiffness of the scaffolds made from the different $\mathrm{P}(3 \mathrm{HB}) / \mathrm{P}(3 \mathrm{HO})$ ratios. The green curve shows the decrease of stiffness after I month of degradation, whereas the blue curve shows a further reduction in stiffness after 4 months of degradation.
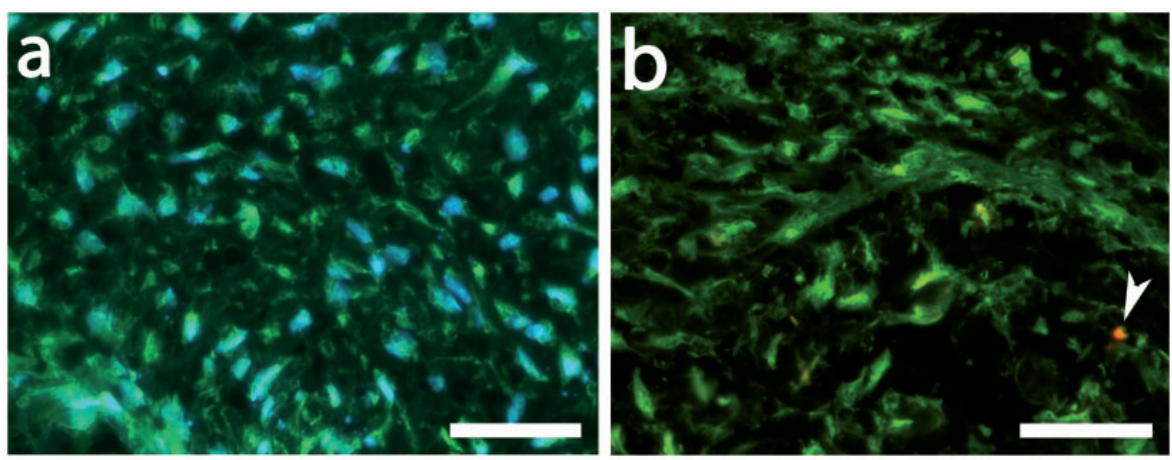

Figure 7. Viability test of $\mathrm{HACs}$-seeded on the $\mathrm{P}(3 \mathrm{HB}) / \mathrm{P}(3 \mathrm{HO}) 1: 0.25$ scaffold. (a) Cell nuclei are shown in blue (DAPI staining), whereas the cell cytoplasm is shown in green (Cell Tracker Green staining). (b) A necrotic cell is shown in red as indicated by the white arrow head (Ethidium Homdimer-I staining). Scale bars: $50 \mu \mathrm{m}$.

Both constructs showed intense Sirius red staining for total collagen matrix at the outer rim of the construct, which was surrounding the Alcian blue staining for proteoglycan matrix at the core of the construct. HACs within the constructs were stained with haematoxylin in black and were located within lacunae, as typically seen in the native AC. Since the histology analysis showed chondrogenesis on the scaffolds, immunohistochemistry was carried out to visualise the presence of specific antigens or proteins in the newly synthesised extracellular matrix.

As shown in Figure 8(b) and ( $\left.b^{\prime}\right)$, the master regulator of chondrocyte differentiation, SOX-9, was immunolocalised in large amounts of chondrocytes. HACs along the periphery exhibited fibroblast-like cell morphology, while those penetrated inside the scaffolds showed the typical rounded morphology of chondrocytes as in their native environment. While significant 


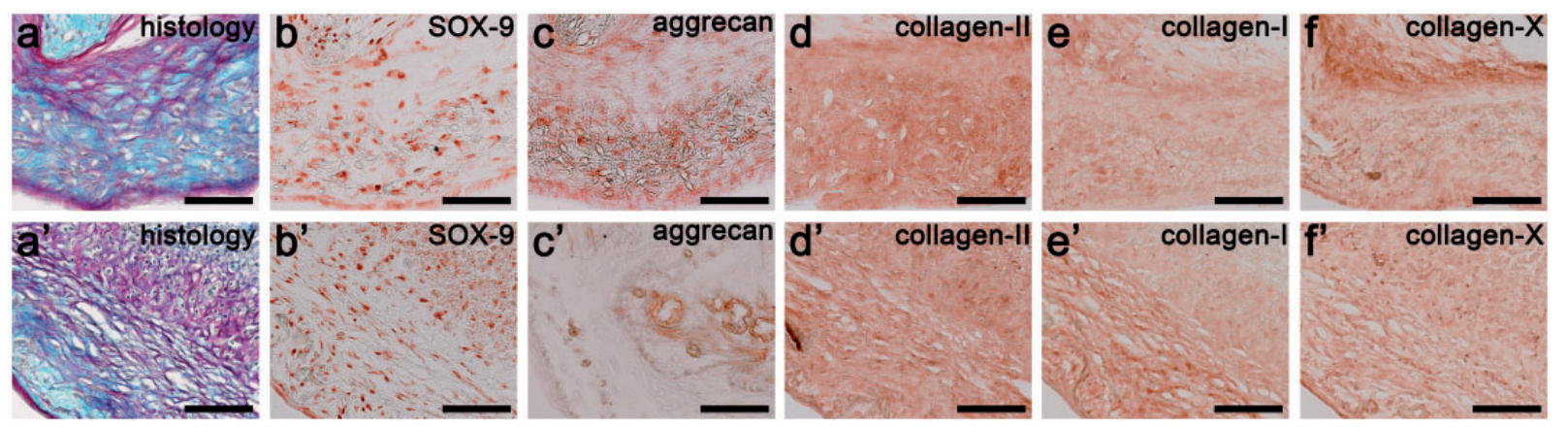

Figure 8. Histology and immunohistochemistry showing cartilage formation on two scaffolds (a-f) $P(3 \mathrm{HB}) / \mathrm{P}(3 \mathrm{HO}) \mathrm{I}: 0.25$ scaffold and (a'-f') $\mathrm{P}(3 \mathrm{HB}) / \mathrm{P}(3 \mathrm{HO})$ I:0.43 scaffold. (a, a') Histology of proteoglycan matrix is shown in blue and the total collagen matrix in red. Cell nuclei are stained with haematoxylin in black. (b-f, b'-f') Immunohistochemistry of (b, b') SOX-9, (c, c') aggrecan, (d, d') type II collagen, (e, e') type I collagen and ( $\left.f, f^{\prime}\right)$ type $X$ collagen. Positive reaction was detected with the chromogenic AEC substrate, which imparts a brownish colour to the cells. Scale bars: $50 \mu \mathrm{m}$.

amount of the cartilage-specific proteoglycan, the aggrecan, was detected on the $\mathrm{P}(3 \mathrm{HB}) / \mathrm{P}(3 \mathrm{HO})$ 1:0.25 scaffold (Figure 8(c)), there was lack of formation of aggrecan on the $\mathrm{P}(3 \mathrm{HB}) / \mathrm{P}(3 \mathrm{HO}) 1: 0.43$ scaffold (Figure $8\left(\mathrm{c}^{\prime}\right)$ ). The positive staining of aggrecan on the $\mathrm{P}(3 \mathrm{HB}) / \mathrm{P}(3 \mathrm{HO})$ 1:0.25 scaffold was mainly detected along with the SOX-9 expressed HACs. We also measured the expression levels of collagen types I, II and X to further determine the quality of our constructs. As shown in Figure $8(\mathrm{~d})$ and $\left(\mathrm{d}^{\prime}\right)$, type II collagen was detected at high levels on both constructs, in most chondrocytes and in the extracellular regions. The expression of the fibrous type I collagen on $\mathrm{P}(3 \mathrm{HB}) / \mathrm{P}(3 \mathrm{HO})$ 1:0.25 scaffold, shown in Figure $8(\mathrm{e})$, was weaker compared to the $\mathrm{P}(3 \mathrm{HB}) / \mathrm{P}(3 \mathrm{HO})$ 1:0.43 scaffold shown in Figure 8( $\left(\mathrm{e}^{\prime}\right)$. Figure 8(f) and $\left(\mathrm{f}^{\prime}\right)$, documents the formation of type $\mathrm{X}$ collagen in both constructs, particularly along the periphery, therefore indicating the presence of hypertrophic chondrocytes.

The distribution of proteoglycan and collagen content in the repair tissue was significantly different compared to native AC. As shown in Figure 9(a), the histology of human AC shows a uniform distribution of collagen content (red) at the surface region and the proteoglycan content (blue) at the inner region. Corresponding to the uniformity of the content, we measured a unimodal stiffness distribution as shown in Figure 9(b). In contrast, and as shown in Figure 9(c), the construct that was cultured for three weeks revealed discrete regions of proteoglycan and total collagen content. This construct exhibited stiffness that varied with the locations being measured, with an average stiffness of $9 \pm 3 \mathrm{kPa}$ at the soft region versus $1061 \pm 600 \mathrm{kPa}$ at the stiff region (Figure 9(d)). The variations in the stiffness distribution are in agreement with the histological analysis. In addition, the thin sheets of electrospun fibres rumpled during cell culturing and were shown as layers in the histology of the construct (Figure 9(c)).

\section{Discussion}

The chondrocytes in native $\mathrm{AC}$ are embedded into the 3D collagen meshwork, which provides a highly specialised fibril surface morphology and chemistry as well as a micromechanical environment that allows chondrogenesis. ${ }^{46}$ Those chemical and physical properties need to be equally implemented into man-made scaffolds to grow functional cartilage. As has been shown, fibrous scaffolds support higher chondrocyte growth rates and improve tissue formation compared to sponge-like ${ }^{47}$ or porous solution cast films. ${ }^{48}$ Here, we employed electrospinning to produce fibrous meshworks from various blends of $\mathrm{P}(3 \mathrm{HB}) / \mathrm{P}(3 \mathrm{HO})$ as 'guiding' structures to direct cartilage repair. $\mathrm{P}(3 \mathrm{HB})$ is a member of the $\mathrm{PHA}$ family of natural biopolymers exhibiting a linear 3-carbon atom polyester with a methyl $\left(\mathrm{CH}_{3}\right)$ side group. The side groups on the polymer chain point away from the centre, which allows the chain to form helical structures that exhibit the minimal steric hindrance. Hence, the chains can easily pack together to form crystals, making the polymer brittle and stiff. To increase its flexibility, the $\mathrm{P}(3 \mathrm{HB})$ polymer can be blended with PHAs of longer pendant chain lengths. For example, $\mathrm{P}(3 \mathrm{HO})$ is a medium-chain-length PHA, also a linear 3-carbon atom polyester but with a pentyl $\left(\mathrm{C}_{5} \mathrm{H}_{11}\right)$ side group. The long alkyl side groups inhibit the close packing of the polymer in a regular 3D fashion to form crystalline array, ${ }^{49}$ thereby decreasing its crystallinity and giving $\mathrm{P}(3 \mathrm{HO})$ its amorphous and flexible properties.

As shown in Figure 2, fibre diameters increased with increasing $\mathrm{P}(3 \mathrm{HO})$ in the blends and can be explained by the reduced crystallinity of $\mathrm{P}(3 \mathrm{HO})$. The superimposition of the stiff and rigid $\mathrm{P}(3 \mathrm{HB})$ with the soft and elastomeric $\mathrm{P}(3 \mathrm{HO})$ in different volume fractions allows to fine tune the mechanical properties of the fibres forming the scaffolds. ${ }^{50}$ 

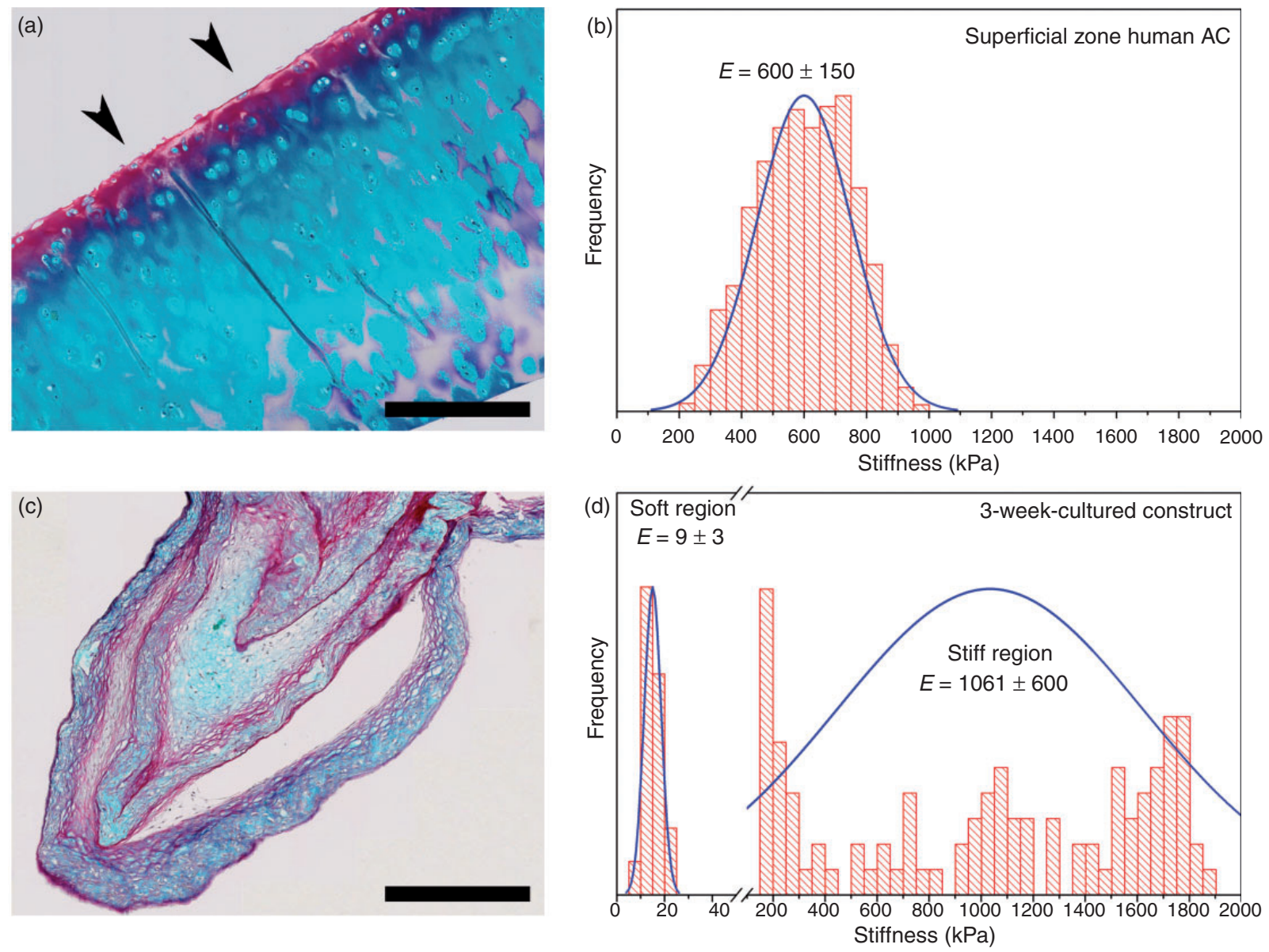

Figure 9. Images and measurements of stiffness of human $A C$ and $H A C s-s e e d e d ~ P(3 H B) / P(3 H O) ~ I: 0.25$ scaffold cultured for 3 weeks. (a) Histology of human AC showing the proteoglycan matrix in blue and total collagen matrix in red (black arrow heads indicate the surface side for stiffness measurement). (b) Stiffness of the superficial zone of human AC shows a unimodal distribution. (c) Histology shows the localised distributions of proteoglycan (blue) and collagen (red) matrix of the construct. (d) The stiffness of the 3-week-cultured construct revealed soft and stiff regions. Scale bars: $200 \mu \mathrm{m}$.

Figure 4 shows the decrease of stiffness and increase of the overall flexibility of scaffolds when increasing the amount of the amorphous $\mathrm{P}(3 \mathrm{HO}){ }^{36,51}$ The diameter of the electrospun fibres depends on the viscosity of polymer solution, the ejection flow rate, the applied voltage and the distance between the spinneret and the collector. The current electrospinning set-up allows to produce fibres with diameters as small as approximately $300 \mathrm{~nm}$ when using $\mathrm{P}(3 \mathrm{HB}) / \mathrm{P}(3 \mathrm{HO})$ ratio of $1: 0.25$. In comparison to these large fibres, chondrocytes in native $\mathrm{AC}$ anchor tightly on collagen fibrils with diameters that are typically between 10 to $300 \mathrm{~nm}^{46,52}$ Smaller diameter fibres similar to the collagen fibrils in AC can be produced by either reducing the viscosity of the polymer solution or by decreasing the ejection flow rate. However, electrospinning of smaller diameter fibres drastically increases the time to produce scaffolds.
Stabilisation of the fibrous scaffolds even without crosslinking agents is provided by the molecular structure of PHAs, which has a carbonyl bond $(\mathrm{C}=\mathrm{O})$ oriented perpendicular to the fibre axis. ${ }^{53}$ The fibrous structure is further stabilised by a hydrogen bond that forms between the $\mathrm{C}=\mathrm{O}$ and $\mathrm{CH}_{3}$ groups $(\mathrm{C}-\mathrm{H} \cdots \mathrm{O}=\mathrm{C}){ }^{54,55}$ At this stage, we decided not to use further (chemical) crosslinking, because the $\mathrm{P}(3 \mathrm{HB}) /$ $\mathrm{P}(3 \mathrm{HO})$ scaffolds were mechanically stable in PBS and could be handled by forceps. As shown in Figure 3, we measured the vibrational frequency of the $\mathrm{C}=\mathrm{O}$ bonds of both $\mathrm{P}(3 \mathrm{HB})$ and $\mathrm{P}(3 \mathrm{HO})$ by using FTIR. The effect of hydrogen bond on the vibrational frequency of $\mathrm{C}=\mathrm{O}$ bonds can be seen as a shift in wavenumbers from $1750-1730 \mathrm{~cm}^{-1}$ towards lower wavenumbers of $1729 \mathrm{~cm}^{-1}$ for $\mathrm{P}(3 \mathrm{HO})$ and $1720 \mathrm{~cm}^{-1}$ for $\mathrm{P}(3 \mathrm{HB}){ }^{56}$ The larger shift for $\mathrm{P}(3 \mathrm{HB})$ can be explained by the stronger hydrogen bond typically found in PHAs, which weakens the $\mathrm{C}=\mathrm{O}$ bond 
and resulting in a lower $\mathrm{C}=\mathrm{O}$ absorption wavenumber. Lower $\mathrm{C}=\mathrm{O}$ absorption wavenumbers are typically measured from a more crystalline structure. ${ }^{45}$ As the crystallinity of the polymer decreases with increasing $\mathrm{P}(3 \mathrm{HO})$, the structure of $\mathrm{P}(3 \mathrm{HO})$ is less ordered and the strength of hydrogen bonding is reduced, resulting in a smaller frequency shift. These variations in the chemical structures based on altered hydrogen bonds allow to systematically develop a toolbox with different $\mathrm{P}(3 \mathrm{HB}) / \mathrm{P}(3 \mathrm{HO})$ blends to produce scaffolds with different functional properties. A higher content of $\mathrm{P}(3 \mathrm{HB})$ may be more suitable for producing scaffolds for stiffer tissues, such as bone, whereas a higher $\mathrm{P}(3 \mathrm{HO})$ content provides more flexible scaffolds for cardiovascular stents, pericardial patches and heart valves.

The degradation rate of scaffolds also controls the space generated in the extracellular matrix to allow cell proliferation and deposition of newly synthesised extracellular matrix. The degraded scaffold structure and stiffness in Figures 5 and 6 show the effects of hydrolytic degradation on the $\mathrm{P}(3 \mathrm{HB}) / \mathrm{P}(3 \mathrm{HO})$ scaffolds. We estimate that the degradation process occurs between one and a few years. ${ }^{57}$ It has been proved that the hydrolytic degradation of PHB proceeds via random chain scission, regardless of the microstructure. ${ }^{58}$ With increasing amounts of $\mathrm{P}(3 \mathrm{HO})$, the degradation rates are slower, because the presence of long alkyl side group sterically hinders the attack of water molecules. ${ }^{37}$ The degradation of PHAs would produce exclusively monomers of PHAs, i.e. 3-hydroxybutyric acids, which naturally occur in various human tissues, ${ }^{32}, 59$ under enzymatic or biological conditions. 3-hydroxybutyric acid monomers are synthesised in the liver from where they are released into the blood stream and absorbed by extrahepatic tissues, such as heart and skeletal muscles, for the generation and utilisation of metabolic energy. Although hydrolysis might not often proceed regioselectively 'cutting' only the last monomeric unit of PHAs, the short-chain products (oligomers) that are formed from hydrolytic degradation are also soluble in water or PBS, and their biocompatibility has been reported. ${ }^{60-61}$ In comparison, the currently used synthetic absorbable polymers, such as PGA and PLA, degrading into 2-hydroxy acids with a $\mathrm{p} K_{a}$ of 3.83 (glycolic acid) and $\mathrm{p} K_{a}$ of 3.08 (lactic acid) and that may cause inflammation, 3-hydroxybutyric acid are significantly less acidic with a lower $\mathrm{p} K_{a}$ of 4.70. ${ }^{62-64}$ It has also been reported that (R)-3-hydroxybutyric acid can increase the cardiac efficiency of heart failure patients, ${ }^{65}$ or act as an alternative energy source to glucose for diabetic patients. ${ }^{66}$

As shown in Figure 7, the high cell viability in threeweek-cultured constructs provided further evidence of the low cytotoxicity of the degradation products released during cell culturing. However, due to the additional enzymatic reactions from cells and tissues, the in vivo degradation rates of the $\mathrm{P}(3 \mathrm{HB}) / \mathrm{P}(3 \mathrm{HO})$ scaffolds may be faster compared to their in vitro degradation rates. ${ }^{57}$ The degradation of $\mathrm{P}(3 \mathrm{HB})$ gastrointestinal patch was accelerated by threefold due to pancreatin enzyme. ${ }^{32}$ However, due to the lack of blood supply in cartilage, the effect of enzymatic action on $\mathrm{P}(3 \mathrm{HB})$ in cartilage is expected to be lower. The degradation time for $\mathrm{P}(3 \mathrm{HB}) / \mathrm{P}(3 \mathrm{HO})$ may vary from one to a few years, but the optimal degradation time constant for the ingrowth of repair cartilage needs to be determined experimentally.

Functional neo-cartilage with biochemical composition, architecture, and mechanical properties that closely mimics native AC may provide the highest clinical success rates for regaining joint function. ${ }^{67,68}$ To evaluate the potential of employing PHA scaffolds for cartilage repair, their ability to maintain high cell viability and cell function is of key importance for chondrocytes to build the complex protein structures and to repair cartilage. $^{27,67,69}$ However, the large majority of previous work was based on synthetic scaffolds that do not degrade and, therefore, do not hamper a proper development of the large proteoglycan and collagen molecules for forming the $3 \mathrm{D}$ tissue matrix. In nondegradable scaffolds, these large molecules are restricted in the lacunae or in the pericellular region as the deposition of large molecules requires more space in the scaffold structure. ${ }^{70}$ As documented by histological analysis of our constructs shown in Figure $8(\mathrm{a})$ and $\left(\mathrm{a}^{\prime}\right)$, the degraded $\mathrm{P}(3 \mathrm{HB}) / \mathrm{P}(3 \mathrm{HO})$ scaffolds provide sufficient space for the newly secreted extracellular matrix. The depletion of oxygen from high levels at the periphery towards hypoxic environment at the centre of the constructs highly influences the quality of the matrix. Although chondrocytes are known to be well adapted to the hypoxic environment within native cartilage tissue, both aerobic and anaerobic metabolic pathways exist in cartilage constructs. ${ }^{71}$ A threshold oxygen level of $8 \%$ has been estimated for HAC in a $3 \mathrm{D}$ pellet culture model, above which collagenous matrix production is favoured, while lower levels of oxygen favour proteoglycan deposition. ${ }^{72} \mathrm{We}$ believe that the use of degrading scaffolds that give space for the development of new matrix proteins is important for producing competent cartilage.

The expression levels of SOX-9 serve as a marker for chondrogenic induction, which includes the production of type II collagen and aggrecan. In a series of key experiments, transfected cells with a vector containing SOX-9 resulted in chondrocytic cells, whereas knocking out of this gene resulted in inhibition of cartilage formation. ${ }^{73}$ As shown in Figure $8(\mathrm{~b})$ and $\left(\mathrm{b}^{\prime}\right)$, large amounts of HACs are of SOX-9 positive, particularly 
among the fine and straight fibres, which indicates that the HACs respond to the morphological features of their surrounding matrix (and maybe also to the growth factor cocktail containing TGF- $\beta$ ). As documented in Figure 8 (d) and $\left(\mathrm{d}^{\prime}\right)$, the high expression levels of type II collagen suggest the formation of hyaline-like cartilage. However, the expression levels of aggrecan in both constructs were different. Aggrecan was formed alongside the SOX-9 expressing cells in the $\mathrm{P}(3 \mathrm{HB}) / \mathrm{P}(3 \mathrm{HO})$ 1:0.25 construct (Figure $8(\mathrm{c})$ ), as SOX-9 promotes the gene expression of aggrecan. Conversely, as shown in Figure 8( $\left.\mathrm{c}^{\prime}\right)$, the chondrocytes in $\mathrm{P}(3 \mathrm{HB}) / \mathrm{P}(3 \mathrm{HO})$ 1:0.43 construct may have de-differentiated, causing the synthesis of small non-cartilaginous proteoglycans and low expression levels of aggrecan. ${ }^{74}$ This is attributed to the differences in the structure and stiffness microenvironment of the constructs. Through cell surface receptors, a cell possesses the ability for tactile sensation. A myriad of physical and chemical (growth factors) signals from the surrounding matrix is transmitted through the various cell surface receptors, which then induces intracellular signalling pathways that regulate gene expression and direct the cells' phenotype. As a result, the complex cell fate processes modulate the formation, function and regeneration of tissue. ${ }^{75}$ The flow of information between cells and their extracellular matrix is reflected in the changes of cell morphology and motility rate in response to changes of their surrounding stiffness. ${ }^{76,77}$ The de-differentiation of chondrocytes is followed by an altered protein expression, including a reduced synthesis of aggrecan and type II collagen. The construct with $\mathrm{P}(3 \mathrm{HB}) / \mathrm{P}(3 \mathrm{HO})$ ratio of 1:0.25 exhibited smaller fibre sizes and higher stiffness compared to that with a ratio of $1: 0.43$, hence, is more closely mimicking the native AC. The lower expression levels of type I collagen in the $\mathrm{P}(3 \mathrm{HB}) / \mathrm{P}(3 \mathrm{HO}) 1: 0.25$ scaffold compared to that on the 1:0.43 scaffold further support the hypothesis that the microenvironment modulates cell fate, protein expression and tissue formation.

The high expression levels of type II collagen in both constructs suggest the development of functional cartilage. However, Figure 8 (f) and ( $\left.\mathrm{f}^{\prime}\right)$, shows relatively high expression levels of type $\mathrm{X}$ collagen in the constructs, pointing to a transition from the chondrocytic phenotype towards the terminal phase of hypertrophic differentiation. One possible explanation for the chondrocyte de-differentiation is that the expression of SOX-9 in the chondrocytes was not continuing throughout the entire culturing period. In addition, the chondrogenic stimuli that employ TGF- $\beta$, dexamethasone and ITS-G can induce chondrogenic differentiation but also promote the up-regulation of type $\mathrm{X}$ collagen. ${ }^{78}$ The potential of matrix calcification induced by type $\mathrm{X}$ collagen may assist in the integration of the newly formed repair tissue with the subchondral bone, or be an indication of cartilage remodelling, which may alter the accumulation of proteoglycans and modifying the diffusion properties of the matrix. ${ }^{79}$ To maintain the normal expression levels of SOX-9 during culturing period remains a challenge in the tissue engineering of cartilage. $^{80}$

The differences in local stiffness properties reflect the local variations in the composition of neo-cartilage compared to the native cartilage. ${ }^{81}$ As shown by the unimodal stiffness distribution on native $\mathrm{AC}$ in Figure 9(b), a spherical indenter with a radius of $5 \mu \mathrm{m}$ was unable to detect the variations in the structural components on the surface of native AC, thereby, indicating that the local structural variations exhibit smaller dimensions. ${ }^{39}$ In comparison, stiffness measurements on the constructs, as shown in Figure 9(d), demonstrate that the variations in the structural components of neo-cartilage were large enough to be detected by the spherical indenter. Discrete soft and stiff regions on the surface were measured, and, therefore, giving an estimate for the heterogeneity of the construct. Considering that cells have a stiffness of three orders of magnitude smaller than the extracellular matrix, and proteoglycans exhibit soft gel-like properties, the low stiffness region of the construct is attributed to the cell- and proteoglycanrich content. Meanwhile, the high stiffness region is attributed to the collagen-rich content or the scaffold structure. ${ }^{40}$ IT-AFM measurements on the three-weekold construct indicate some promising hyaline-like cartilage formation. However, further in vivo experiments will allow to investigate the performance of these scaffolds in the specific microenvironment of living organisms.

\section{Conclusion}

Unlike the self-healing abilities in some other species, the human body needs a supporting structure with a close-to-native microenvironment that aids as a template to direct the growth of cartilage. Any deviation of physical or chemical properties from what a cell experiences in its native microenvironment may cause de-differentiation of chondrocytes and may lead to altered protein expressions. By following nature's design principles, we electrospun $\mathrm{P}(3 \mathrm{HB}) / \mathrm{P}(3 \mathrm{HO})$ blends to mimic the collagen meshwork in AC. The ultrastructure and mechanical properties of the scaffolds in combination are vitally important in providing a microenvironment that favours the differentiation of chondrocytes and neo-cartilage growth. Based on our results, we believe that the $\mathrm{P}(3 \mathrm{HB}) / \mathrm{P}(3 \mathrm{HO})$ scaffolds can be developed into a clinical repair product to heal cartilage defects and avoid the development of secondary osteoarthritis. In addition, the biodegradable 
blends of $\mathrm{P}(3 \mathrm{HB}) / \mathrm{P}(3 \mathrm{HO})$ may allow to establish a toolbox with tailored scaffolds for the repair of a variety of other tissues such as bone, pericardial patches, or biodegradable cardiovascular stents.

\section{Acknowledgements}

The authors would like to thank Professor Robert J.K. Wood for supporting this research and Professor Richard Oreffo for providing his research facilities for the biocompatibility tests. We acknowledge the support from the Scholarships Committee of the University of Westminster for the support to Dr Pooja Basnett.

\section{Declaration of conflicting interests}

The author(s) declared no potential conflicts of interest with respect to the research, authorship, and/or publication of this article.

\section{Funding}

The author(s) received no financial support for the research, authorship, and/or publication of this article.

\section{References}

1. Hunter W. On the structure and diseases of articulating cartilage. Philos Trans R Soc Lond B Biol Sci 1743; 42: 514-521.

2. Pridie KH. A method of resurfacing osteoarthritic knee joints. J Bone Joint Surg Br 1959; 41: 618-619.

3. Johnson LL. Arthroscopic abrasion arthroplasty historical and pathologic perspective: Present status. Arthroscopy 1986; 2: 54-69.

4. Steadman JR, Rodkey WG, Singleton SB, et al. Microfracture technique for full-thickness chondral defects: technique and clinical results. Oper Tech Orthop 1997; 7: 300-304.

5. Mithoefer K, Mcadams T, Williams RJ, et al. Clinical efficacy of the microfracture technique for articular cartilage repair in the knee: An evidence-based systematic analysis. Am J Sports Med 2009; 37: 2053-2063.

6. Sharma B, Fermanian S, Gibson M, et al. Human cartilage repair with a photoreactive adhesive-hydrogel composite. Sci Transl Med 2013; 5: 167ra166.

7. Brittberg M, Lindahl A, Nilsson A, et al. Treatment of deep cartilage defects in the knee with autologous chondrocyte transplantation. N Engl J Med 199; 331: 889-895.

8. Briggs TW, Mahroof S, David LA, et al. Histological evaluation of chondral defects after autologous chondrocyte implantation of the knee. J Bone Joint Surg Br 2003; 85: 1077-1083.

9. Horas U, Pelinkovic D, Herr G, et al. Autologous chondrocyte implantation and osteochondral cylinder transplantation in cartilage repair of the knee joint. A prospective, comparative trial. J Bone Joint Surg Am 2003; 85: 185-192.

10. Knutsen G, Engebretsen L, Ludvigsen $\mathrm{TC}$, et al. Autologous chondrocyte implantation compared with microfracture in the knee. A randomized trial. $J$ Bone Joint Surg Am 2004; 86: 455-464.

11. Schneider U and Andereya S. First results of a prospective randomized clinical trial on traditional chondrocyte transplantation vs cares-technology. Z Orthop Ihre Grenzgeb 2003; 141: 496-497.

12. Behrens P, Bitter T, Kurz B, et al. Matrix-associated autologous chondrocyte transplantation/implantation (mact/maci) - 5-year follow-up. Knee 2006; 13: 194-202.

13. Marcacci M, Berruto M, Brocchetta $D$, et al. Articular cartilage engineering with Hyalograft C: 3-year clinical results. Clin Orthop Relat Res 2005; 435: 96-105.

14. Stanish WD, Mccormack R, Forriol F, et al. Novel scaffold-based bst-cargel treatment results in superior cartilage repair compared with microfracture in a randomized controlled trial. J Bone Joint Surg Am 2013; 95: 1640-1650.

15. Regentis Biomaterials Ltd. Gelrinc. A novel, acellular treatment for cartiage lesions on the femoral condyle. White paper, Or Akiva, Israel, 2014.

16. Bryant SJ and Anseth KS. Hydrogel properties influence ecm production by chondrocytes photoencapsulated in poly(ethylene glycol) hydrogels. J Biomed Mater Res 2002; 59: 63-72.

17. Mikos AG, Sarakinos G, Leite SM, et al. Laminated three-dimensional biodegradable foams for use in tissue engineering. Biomaterials 1993; 14: 323-330.

18. Freed LE, Vunjak-Novakovic G, Biron RJ, et al. Biodegradable polymer scaffolds for tissue engineering. Nat Biotechnol 1994; 12: 689-693.

19. Li WJ, Cooper JA, Mauck RL, et al. Fabrication and characterization of six electrospun poly(alpha-hydroxy ester)-based fibrous scaffolds for tissue engineering applications. Acta Biomater 2006; 2: 377-385.

20. Ossendorf C, Kaps C, Kreuz PC, et al. Treatment of posttraumatic and focal osteoarthritic cartilage defects of the knee with autologous polymer-based three-dimensional chondrocyte grafts: 2-year clinical results. Arthritis Res Ther 2007; 9: R41.

21. Carmont MR, Carey-Smith R, Saithna A, et al. Delayed incorporation of a trufit plug: Perseverance is recommended. Arthroscopy 2009; 25: 810-814.

22. Lee SJ, Han SI and Shim IK. Fibrous 3-dimensional scaffold via electrospinning for tissue regeneration and method for preparing the same. Patent 12/064,801, USA, 2008.

23. Sung HJ, Meredith C, Johnson C, et al. The effect of scaffold degradation rate on three-dimensional cell growth and angiogenesis. Biomaterials 2004; 25 : 5735-5742.

24. Bergsma JE, De Bruijn WC, Rozema FR, et al. Late degradation tissue response to poly(l-lactide) bone plates and screws. Biomaterials 1995; 16: 25-31.

25. Athanasiou KA, Niederauer GG and Agrawal CM. Sterilization, toxicity, biocompatibility and clinical applications of polylactic acid/polyglycolic acid copolymers. Biomaterials 1996; 17: 93-102.

26. Gunatillake PA and Adhikari R. Biodegradable synthetic polymers for tissue engineering. Eur Cell Mater 2003; 5: $1-16$. 
27. Huey DJ, Hu JC and Athanasiou KA. Unlike bone, cartilage regeneration remains elusive. Science 2012; 338: 917-921.

28. Reilly GC and Engler AJ. Intrinsic extracellular matrix properties regulate stem cell differentiation. $J$ Biomech 2010; 43: 55-62.

29. Weaver VM, Petersen OW, Wang F, et al. Reversion of the malignant phenotype of human breast cells in threedimensional culture and in vivo by integrin blocking antibodies. J Cell Biol 1997; 137: 231-245.

30. Bissell MJ and Hines WC. Why don't we get more cancer? A proposed role of the microenvironment in restraining cancer progression. Nat Med 2011; 17: 320-329.

31. Chaudhuri O, Koshy ST, Branco Da, et al. Extracellular matrix stiffness and composition jointly regulate the induction of malignant phenotypes in mammary epithelium. Nat Mater 2014; 13: 970-978.

32. Chen GQ and Wu Q. The application of polyhydroxyalkanoates as tissue engineering materials. Biomaterials 2005; 26: 6565-6578.

33. Kawalec M, Sitkowska A, Sobota M, et al. Human procollagen type I surface-modified PHB-based non-woven textile scaffolds for cell growth: Preparation and shortterm biological tests. Biomed Mater 2014; 9: 065005.

34. Hutmacher DW. Scaffolds in tissue engineering bone and cartilage. Biomaterials 2000; 21: 2529-2543.

35. Eglin D, Mortisen D and Alini M. Degradation of synthetic polymeric scaffolds for bone and cartilage tissue repairs. Soft Matter 2009; 5: 938-947.

36. Rai R, Yunos DM, Boccaccini AR, et al. Poly-3hydroxyoctanoate $\mathrm{P}(3 \mathrm{HO})$, a medium chain length polyhydroxyalkanoate homopolymer from pseudomonas mendocina. Biomacromolecules 2011; 12: 2126-2136.

37. Basnett P, Ching KY, Stolz M, et al. Novel poly(3-hydroxyoctanoate)/poly(3-hydroxybutyrate) blends for medical applications. React Funct Polym 2013; 73: 1340-1348.

38. Stolz M, Raiteri R, Daniels A, et al. Dynamic elastic modulus of porcine articular cartilage determined at two different levels of tissue organization by indentation-type atomic force microscopy. Biophys $J$ 2004; 86: 3269-3283.

39. Stolz M, Gottardi R, Raiteri R, et al. Early detection of aging cartilage and osteoarthritis in mice and patient samples using atomic force microscopy. Nat Nanotechnol 2009; 4: 186-192.

40. Loparic M, Wirz D, Daniels AU, et al. Micro- and nanomechanical analysis of articular cartilage by indentationtype atomic force microscopy: Validation with a gel-microfiber composite. Biophys J 2010; 98: 2731-2740.

41. Bueckle H. The science of hardness testing and its research applications. In: Westbrook $\mathrm{JH}$, Conrad $\mathrm{H}$ (eds) The science of hardness testing and its research applications. Ohio: American Society for Metals, 1973.

42. Oliver WC and Pharr GM. An improved technique for determining hardness and elastic modulus using load and displacement sensing indentation experiments. J Mater Res 1992; 7: 1564-1583.

43. De Andres MC, Imagawa $\mathrm{K}$, Hashimoto $\mathrm{K}$, et al. Suppressors of cytokine signalling (socs) are reduced in osteoarthritis. Biochem Biophys Res Commun 2011; 407: 54-59.

44. Malpeli M, Randazzo N, Cancedda R, et al. Serum-free growth medium sustains commitment of human articular chondrocyte through maintenance of SOX9 expression. Tissue Eng 2004; 10: 145-155.

45. Kansiz M, Dominguez-Vidal A, Mcnaughton D, et al. Fourier-transform infrared (FTIR) spectroscopy for monitoring and determining the degree of crystallisation of polyhydroxyalkanoates (PHAs). Anal Bioanal Chem 2007; 388: 1207-1213.

46. Mankin HJ, Mow VC and Buckwalter JA. Articular cartilage structure, composition, and function. In: Buckwalter JA, Einhorn TA, Simon SR (eds) Orthopaedic basic science: Biology and biomechanics of the musculoskeletal system. Illinois: American Academy of Orthopaedic Surgeons, 2000.

47. Freed LE, Marquis JC, Nohria A, et al. Neocartilage formation in vitro and in vivo using cells cultured on synthetic biodegradable polymers. J Biomed Mater Res 1993; 27: 11-23.

48. Lee I, Kwon O, Meng W, et al. Nanofabrication of microbial polyester by electrospinning promotes cell attachment. Macromol Res 2004; 12: 374-378.

49. Sanchez RJ, Schripsema J, Da Silva LF, et al. Mediumchain-length polyhydroxyalkanoic acids (PHA(mcl)) produced by pseudomonas putida ipt 046 from renewable sources. Eur Polym J 2003; 39: 1385-1394.

50. Dufresne A and Vincendon M. Poly(3-hydroxybutyrate) and poly(3-hydroxyoctanoate) blends: morphology and mechanical behavior. Macromolecules 2000; 33 : 2998-3008.

51. Asrar J, Valentin HE, Berger PA, et al. Biosynthesis and properties of poly(3-hydroxybutyrate-co-3-hydroxyhexanoate) polymers. Biomacromolecules 2002; 3: 1006-1012.

52. Mow VC, Gu WY and Chen FH. Structure and function of articular cartilage and meniscus. In: Mow VC, Huiskes R (eds) Basic orthopaedic biomechanics and mechano-biology. Pennsylvania: Lippincott Williams \& Wilkins, 2005.

53. Chan KHK, Wong SY, Li X, et al. Effect of molecular orientation on mechanical property of single electrospun fiber of poly[(r)-3-hydroxybutyrate-co-(r)-3-hydroxyvalerate]. J Phys Chem B 2009; 113: 13179-13185.

54. Sato H, Murakami R, Padermshoke A, et al. Infrared spectroscopy studies of $\mathrm{CH}$... O hydrogen bondings and thermal behavior of biodegradable poly(hydroxyalkanoate). Macromolecules 2004; 37: 7203-7213.

55. Hu Y, Zhang JM, Sato H, et al. C-H. .O $=\mathrm{C}$ hydrogen bonding and isothermal crystallization kinetics of poly(3hydroxybutyrate) investigated by near-infrared spectroscopy. Macromolecules 2006; 39: 3841-3847.

56. Stuart B. Infrared spectroscopy: fundamentals and applications. New Jersey: John Wiley \& Sons, 2004.

57. Marois Y, Zhang Z, Vert M, et al. In vivo biocompatibility and degradation studies of polyhydroxyoctanoate in the rat: a new sealant for the polyester arterial prosthesis. Tissue Eng 1999; 5: 369-386.

58. Kurcok P, Kowalczuk M, Adamus G, et al. Degradability of PHB. Correlation with chemical 
microstructure. J Macromol Sci Pure Appl Chem 1995; A32: 875-880.

59. Scandola M, Focarete ML, Adamus G, et al. Polymer blends of natural poly(3-hydroxybutyrate-co-3-hydroxyvalerate) and a synthetic atactic poly(3-hydroxybutyrate). Characterization and biodegradation studies. Macromolecules 1997; 30: 2568-2574.

60. Gogolewski S, Jovanovic M, Perren SM, et al. Tissue response and in vivo degradation of selected polyhydroxyacids: polylactides (PLA), poly(3-hydroxybulyrate) (PHB), and poly(3-hydroxybulyrate-co-3-hydroxyvalerate) (PHB/VA). J Biomed Mater Res 1993; 27: 1135-1148.

61. Piddubnyak V, Kurcok P, Matuszowicz A, et al. Oligo-3hydroxybutyrates as potential carriers for drug delivery. Biomaterials 2004; 25: 5271-5279.

62. Taylor MS, Daniels AU, Andriano KP, et al. Six bioabsorbable polymers: In vitro acute toxicity of accumulated degradation products. J Appl Biomater 1994; 5: 151-157.

63. Weng YX, Wang XL and Wang YZ. Biodegradation behavior of phas with different chemical structures under controlled composting conditions. Polym Test 2011; 30: 372-380.

64. Chen Q, Liang S and Thouas GA. Elastomeric biomaterials for tissue engineering. Prog Polym Sci 2013; 38: 584-671.

65. Sato K, Kashiwaya Y, Keon CA, et al. Insulin, ketone bodies, and mitochondrial energy transduction. FASEB J 1995; 9: 651-658.

66. Gumbiner B, Wendel JA and Mcdermott MP. Effects of diet composition and ketosis on glycemia during verylow-energy-diet therapy in obese patients with non-insulin-dependent diabetes mellitus. Am J Clin Nutr 1996; 63: $110-115$.

67. Lebaron RG and Athanasiou KA. Ex vivo synthesis of articular cartilage. Biomaterials 2000; 21: 2575-2587.

68. Athanasiou KA, Darling EM and Hu JC. Articular cartilage tissue engineering. California: Morgan \& Claypool Publishers, 2009.

69. Stevens MM and George JH. Exploring and engineering the cell surface interface. Science 2005; 310: 1135-1138.

70. Bryant SJ, Bender RJ, Durand KL, et al. Encapsulating chondrocytes in degrading peg hydrogels with high modulus: engineering gel structural changes to facilitate cartilaginous tissue production. Biotechnol Bioeng 2004; 86: 747-755.

71. Malda J, Martens DE, Tramper J, et al. Cartilage tissue engineering: controversy in the effect of oxygen. Crit Rev Biotechnol 2003; 23: 175-194.

72. Li S, Oreffo ROC, Sengers BG, et al. The effect of oxygen tension on human articular chondrocyte matrix synthesis: integration of experimental and computational approaches. Biotechnol Bioeng 2014; 111: 1876-1885.

73. Bi W, Huang W, Whitworth DJ, et al. Haploinsufficiency of sox 9 results in defective cartilage primordia and premature skeletal mineralization. Proc Natl Acad Sci USA 2001; 98: 6698-6703.

74. Vonwil D. Chondro progenitor cell response to specifically modified substrate interfaces. PhD Thesis, University of Basel, Switzerland, 2010.

75. Lutolf MP and Hubbell JA. Synthetic biomaterials as instructive extracellular microenvironments for morphogenesis in tissue engineering. Nat Biotechnol 2005; 23: 47-55.

76. Lo CM, Wang HB, Dembo M, et al. Cell movement is guided by the rigidity of the substrate. Biophys $J$ 2000; 79: 144-152.

77. Discher DE, Janmey P and Wang YL. Tissue cells feel and respond to the stiffness of their substrate. Science 2005; 310: 1139-1143.

78. Johnstone B, Alini M, Cucchiarini M, et al. Tissue engineering for articular cartilage repair - the state of the art. Eur Cell Mater 2013; 25: 248-267.

79. Richardson JB, Caterson B, Evans EH, et al. Repair of human articular cartilage after implantation of autologous chondrocytes. J Bone Joint Surg Br 1999; 81: 1064-1068.

80. Hiramatsu K, Sasagawa S, Outani H, et al. Generation of hyaline cartilaginous tissue from mouse adult dermal fibroblast culture by defined factors. J Clin Invest 2011; 121: 640-657.

81. Klein TJ, Chaudhry M, Bae WC, et al. Depth-dependent biomechanical and biochemical properties of fetal, newborn, and tissue-engineered articular cartilage. $J$ Biomech 2007; 40: 182-190. 